The work of McCarron et al has provided clear evidence that substantial changes in blood pressure levels can occur, and both these and other data suggest that such changes can occur in broad population groups. New epidemiological studies that provide reliable information about the most likely causes of these changes, and new large scale randomised trials that identify effective means of changing population levels of blood pressure, are needed. To have the greatest impact on the global burden of cardiovascular disease, however, the data from such studies must be directly applicable to the social, cultural, and economic circumstances of the less affluent sections of the global community.
Competing interests: None declared.

1 MacMahon S, Peto R, Cutler J, Collins R, Sorlie P, Neaton J, et al. Blood pressure, stroke, and coronary heart disease. Part 1. Prolonged differences in blood pressure: prospective observational studies corrected for the regression dilution bias. Lancet 1990;335:765-74

2 Blood Pressure Lowering Treatment Trialists' Collaboration. Effects of ACE inhibitors, calcium antagonists and other blood pressure lowering drugs: results of prospectively designed overviews of randomised trials. Lancet 2000;356:1955-64.

3 Rodgers A, Lawes C, MacMahon S. Reducing the global burden of blood pressure-related disease. J Hypertens 2000;18(suppl 1):S3-6.

4 Bonita R, Stewart A, Beaglehole R. International trends in stroke mortality: 1970-1985. Stroke 1990;21:989-92.

5 Marmot M, Adelstein A, Robinson N, Rose G. Changing social-class distribution of heart disease. BMJ 1978;2:1109-12.

6 Murray CJL, Lopez AD. Global patterns of cause of death and burden of disease in 1990, with projections to 2020. In: Investing in health research and development. Report of the Ad Hoc Committee on Health Research Relating to Future Intervention Options. Geneva: World Health Organization, 1996.

\title{
Birth weight and childhood onset type 1 diabetes: population based cohort study
}

\author{
Lars C Stene, Per Magnus, Rolv T Lie, Oddmund Søvik, Geir Joner and The Norwegian Childhood \\ Diabetes Study Group
}

\begin{abstract}
Objective To assess the associations between birth weight or gestational age and risk of type 1 diabetes. Design Population based cohort study by record linkage of the medical birth registry and the National Childhood Diabetes Registry.

Setting Two national registries in Norway. Participants All live births in Norway between 1974 and 1998 (1 382602 individuals) contributed a maximum of 15 years of observation, a total of 8184994 person years of observation in the period 1989 to 1998 . 1824 children with type 1 diabetes were diagnosed between 1989 and 1998 .

Main outcome measures Estimates of rate ratios with $95 \%$ confidence intervals for type 1 diabetes from Poisson regression analyses.

Results The incidence rate of type 1 diabetes increased almost linearly with birth weight. The rate ratio for children with birth weights $4500 \mathrm{~g}$ or more compared with those with birth weights less than $2000 \mathrm{~g}$ was 2.21 (95\% confidence interval 1.24 to 3.94), test for trend $\mathrm{P}=0.0001$. There was no significant association between gestational age and type 1 diabetes. The results persisted after adjustment for maternal diabetes and other potential

confounders.

Conclusion There is a relatively weak but significant association between birth weight and increased risk of type 1 diabetes consistent over a wide range of birth weights.
\end{abstract}

\section{Introduction}

Type 1 diabetes mellitus results from an immune mediated destruction of the pancreatic $\beta$ cells. The factors initiating the destructive process are largely unknown, but genetic and non-genetic factors are involved. ${ }^{1}$ Putative environmental risk factors such as viruses or nutritional factors may play a part early in life, possibly in utero. ${ }^{2}$ An association between high birth weight or high birth weight for gestational age and increased risk of type 1 diabetes has been found in some relatively large case-control studies, even after exclusion of data from children whose mother had diabetes in pregnancy. ${ }^{3-5}$ On the other hand, several other case-control studies have not found any significant association. ${ }^{6-14}$ The magnitude of the association between birth weight and type 1 diabetes seems to be relatively small, and the lack of significant association in the latter studies may be explained by insufficient statistical power. We estimated the associations between birth weight and gestational age and the incidence rate of type 1 diabetes in a large population based cohort study that provided sufficient power to estimate these associations over a wide range of values.

\section{Participants and methods}

\section{Participants}

Since the beginning of 1989 all newly diagnosed cases of type 1 diabetes diagnosed in children aged up to 15 years in Norway have been prospectively registered with a high level of ascertainment in the National Childhood Diabetes Registry. ${ }^{15}$ We designed a cohort study by record linkage of the Medical Birth Registry of Norway and the childhood diabetes registry through the unique personal identification number assigned to all residents of Norway. Out of 1863 cases of type 1 diabetes diagnosed between 1 January 1989 and 31 December 1998, 1824 were linked. All live births in Norway between 1974 and 1998 contributed time under observation from birth to diagnosis of type 1 diabetes, age 15 years, or 31 December 1998, whichever occurred first. As registration of cases started in 1989, the time under observation was counted only from 1 January 1989 for those born before this date. Deaths in the first year of life were

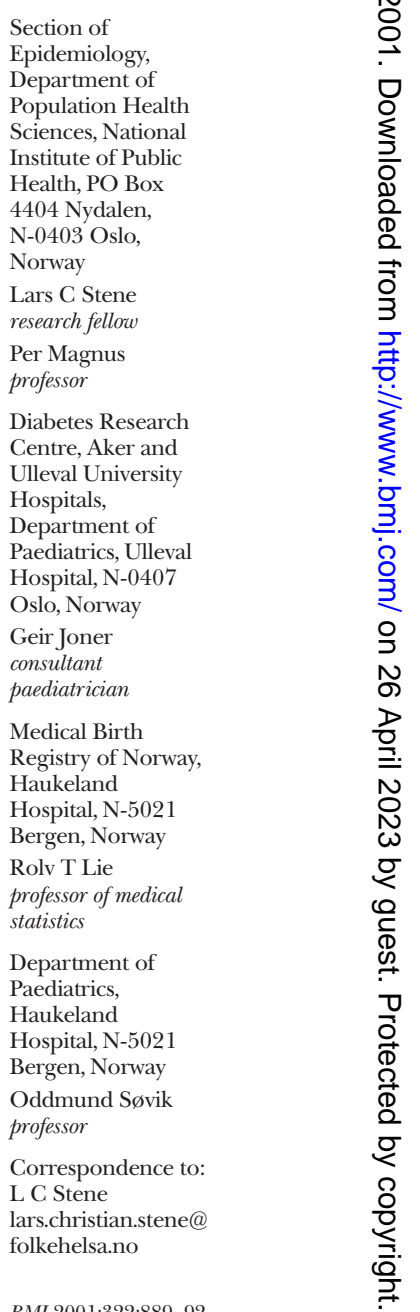

BMJ 2001;322:889-92 
censored, but we did not have information on deaths between age 1 and 15 years of age. A total of 1382602 individuals contributed 8184994 person years of observation between 1989 and 1998. The mean (SD) time from birth to censoring was 10.2 (5.0) years, and the mean time under observation after 1 January 1989 was 5.9 (3.3) years. The mean age at diagnosis among the 1824 who developed type 1 diabetes was 8.6 (3.7) years. The study was approved by the regional ethics committee and the national data inspectorate.

\section{Data analysis}

From the entire cohort we excluded from analysis 2468 individuals $(0.2 \%)$ with missing data on birth weight, including three who developed type 1 diabetes. Gestational age was calculated from the first day of bleeding in the last menstruation. Those with missing data on gestational age $(6.9 \%)$ were included. We calculated the number of incident cases $\left(D_{j}\right)$ and person time under observation $\left(T_{j}\right)$ in each exposure category (j) using DATAB in the EPICURE package, version $1.8 w .{ }^{16}$ Incidence rates were calculated as $D_{j} / T_{j}$. To assess a "dose-response" relation we plotted incidence rates against median birth weight in seven categories and against median gestational age in six categories and a category for missing data. We calculated confidence intervals for the incidence rates based on the Poisson assumption and using a log transformation. We used the AMFIT program of EPICURE to fit Poisson regression models, providing estimated rate ratios with $95 \%$ confidence intervals. We use the likelihood ratio test for birth weight entered as a continuous variable to test for trend.

We considered sex, maternal age at delivery $(<25$, $25-30$, and $\geqslant 30$ years), maternal parity $(0, \geqslant 1)$, caesarean section, maternal pre-eclampsia, attained age (0-4.9, 5-9.9, and 10-14.9 years), and calendar period of birth (1974-83, 1984-90, and 1991-8) as potential confounders. We did stratified analyses and included potential confounders in the regression models, both one by one and all covariates together to assess confounding. The effect of excluding multiple births and maternal diabetes mellitus (any type) diagnosed before or during the index pregnancy was also investigated. To test whether the association of birth weight and type 1 diabetes was homogenous in different age groups and in different categories of gestational age, we tested the significance of the respective interaction terms. We regarded a two sided $\mathrm{P}$ value less than 0.05 or a $95 \%$ confidence interval excluding the value 1.0 for the rate ratio as significant.

\section{Results}

Figure 1 shows that the incidence rate of type 1 diabetes increased almost linearly with birth weight. The rate ratio for the highest category of birth weight $(\geqslant 4500 \mathrm{~g})$ compared with the lowest $(<2000 \mathrm{~g})$ was 2.21 , and the trend was highly significant (table). The estimates were virtually unchanged after stratification by gestational age or exclusion of children whose mother had diabetes in pregnancy and multiple births or after adjustment for other potential confounders. The simple Poisson regression model predicted a 1.7\% increase in incidence rate per $100 \mathrm{~g}$ increase in birth weight (95\% confidence interval $0.9 \%$ to $2.6 \%)$.

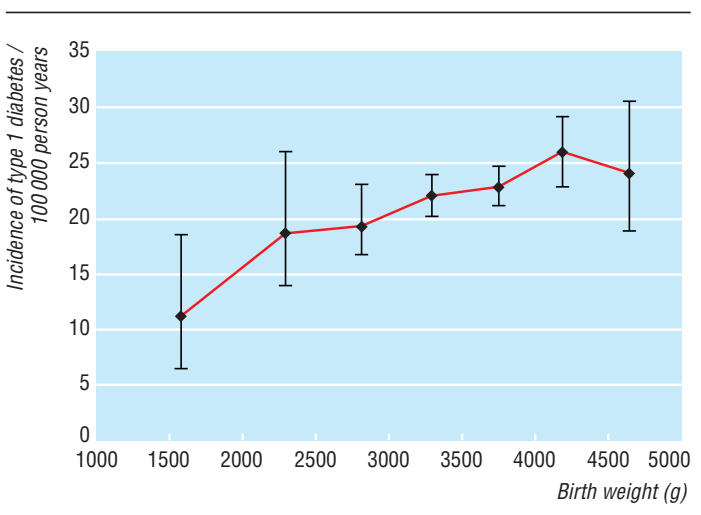

Fig 1 Birth weight and incidence rate of type 1 diabetes with 95\% confidence intervals. Birth weight values are medians in categories $<2000$ g, 2000-2499 g, 2500-2999 g, 3000-3499 g, 3500-3999 g, $4000-4499 \mathrm{~g}$, and $\geqslant 4500 \mathrm{~g}$

Rate ratios for type 1 diabetes by birth weight in Norwegian children*

\begin{tabular}{lccl} 
Birth weight $(\mathbf{g})$ & Incident cases & Person years & Rate ratio $\mathbf{( 9 5 \% ~ C I )}$ \\
\hline$<2000$ & 14 & 129522 & 1.00 (reference) \\
\hline $2000-2499$ & 41 & 214995 & $1.76(0.96$ to 3.24$)$ \\
\hline $2500-2999$ & 174 & 884884 & $1.82(1.06$ to 3.14$)$ \\
\hline $3000-3499$ & 561 & 2566646 & $2.02(1.19$ to 3.44$)$ \\
\hline $3500-3999$ & 648 & 2846744 & $2.11(1.24$ to 3.58$)$ \\
\hline $4000-4499$ & 316 & 1229034 & $2.38(1.39$ to 4.06$)$ \\
\hline$\geqslant 4500$ & 67 & 279978 & $2.21(1.24$ to 3.94$)$ \\
\hline
\end{tabular}

${ }^{\star} \mathrm{P}=0.0001$ for test for trend over all birth weights.

Figure 2 shows the dose-response relation between gestational age and the incidence rate of type 1 diabetes. In Poisson regression analyses there was no significant association between gestational age and type 1 diabetes, neither crude nor after adjustment for potential confounders or exclusion of extreme values (data not shown).

The contribution to the person time from children who died in the first year of life was counted only until their death because of the known increased infant mortality in low birthweight infants. Low birth weight has also been associated with deaths in children between the ages of 1 and 15 years, which would potentially overestimate our observed rate ratio. ${ }^{17}$

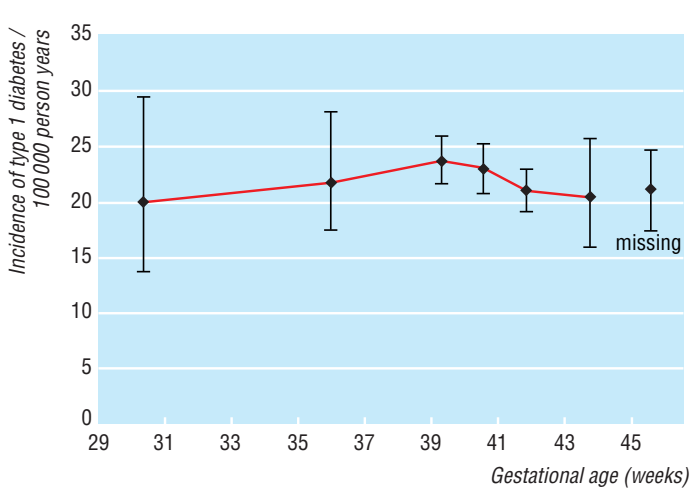

Fig 2 Gestational age and incidence rate of type 1 diabetes with $95 \%$ confidence intervals. Gestational age values are medians in categories $<34$, 34-36.9, 37-39.9, 40-40.9, 41-42.9, and $\geqslant 43$ weeks (missing category is arbitrarily placed at 45.5 weeks) 
However, the cumulative mortality between 1 and 15 years is small. Using the data from Samuelsen et al, ${ }^{17}$ we calculated that the expected bias in our estimated rate ratio would be less than $1 \%$ (data not shown).

\section{Discussion}

Our most important finding was a linear increase in the incidence of type 1 diabetes with increasing birth weight over a wide range of birth weights, independent of gestational age, maternal diabetes, and other potential confounders.

The advantage of this study is the large sample size and the fact that the data are based on computerised registries with nearly complete coverage. Furthermore, we were able to take into account other potential confounders, such as maternal diabetes, sex, gestational age, maternal age at delivery, maternal parity, caesarean section, and pre-eclampsia. As the incidence rate of childhood onset type 1 diabetes in Norway remained stable in the study period ${ }^{15}{ }^{18}$ and the association between birth weight and type 1 diabetes persisted after adjustment for calendar period of birth, it is unlikely that time trends have resulted in a spurious association between birth weight and type 1 diabetes. As in all non-experimental research, we cannot exclude the possibility that unmeasured factors were confounders. We did not have information on socioeconomic status of the children's families, such as maternal education or on maternal smoking during pregnancy. However, maternal education is unlikely to explain our results as high maternal education is associated with increased birth weight and has been weakly associated with a decreased risk of type 1 diabetes. ${ }^{6}{ }^{19}$

\section{Comparison with previous studies}

Our data support the results of some relatively large studies, ${ }^{3-5}{ }^{20}$ as well as a study in experimental animals. ${ }^{21}$ In a large population based study from Sweden, however, Dahlquist et al found an association between birth weight relative to the average for any particular gestational age and type 1 diabetes but no significant association with birth weight per se. ${ }^{3}$ This apparent discrepancy is difficult to explain. Dahlquist et al adjusted for maternal smoking during pregnancy in a subset of their data, indicating that maternal smoking did not influence their result. ${ }^{3}$ Consistent with our observation, an increase in both mean birth weight and the incidence of type 1 diabetes has been observed in many Western countries in the past two to three decades. ${ }^{22}{ }^{23}$ However, the magnitude of the association between birth weight and type 1 diabetes was estimated as a $1.7 \%$ increase in incidence rate per $100 \mathrm{~g}$ increase in birth weight, which is probably not sufficient to explain these secular trends in type 1 diabetes. Detection of such a relatively weak association requires a large sample size. For instance, 2500 cases and 2500 controls are needed to attain $80 \%$ power to detect a significant association between birth weights of $2500 \mathrm{~g}$ and more versus less than $2500 \mathrm{~g}$ and type 1 diabetes in a case-control study if the true odds ratio is 1.5 and $5 \%$ of the population have birth weights less than $2500 \mathrm{~g}$. This indicates that most of the published casecontrol studies may have had far too little power to detect such an association.
What is already known on this topic

Results of case-control studies of birth weight and risk of type 1 diabetes have been inconsistent

It is possible that a relatively weak association exists, and large studies are needed to find out if this is the case

\section{What this study adds}

This is the largest study of birth weight and type 1 diabetes published to date, and the first one to use a cohort design

The incidence of type 1 diabetes increased almost linearly with increasing birth weight over a wide range of birth weights, independent of gestational age, maternal diabetes, and other potential confounders

The trend was highly significant, but the increment in risk with increasing birth weight was still relatively low

\section{Possible explanations}

Both birth weight and gestational age are influenced by several factors, such as maternal diabetes during pregnancy, nutrition, and parity, and may be viewed as markers of the combined effect of many factors. Potential factors explaining the present results would have to be associated with both increased birth weight and increased risk of type 1 diabetes over a wide range of birth weights. Maternal diabetes is one such candidate but is not likely to explain the observed association as the association persisted after exclusion of data from children whose mother had diabetes in pregnancy. As only a very small proportion of the children had a mother with diabetes diagnosed before or during pregnancy $(0.5 \%)$, even a hypothetical underreporting of maternal diabetes is unlikely to explain the observed association. This indicates that other rare conditions probably do not explain the observed relation either. We cannot exclude the possibility that some genetic factors predispose to both higher birth weight and type 1 diabetes. A common genetic variant of the insulin gene region has been associated with lower birth weight in one study, but the effect was weak and significant only in a subgroup. ${ }^{24}$ The same variant is associated with an increased risk of type 1 diabetes. ${ }^{25}$ Allelic variation in the insulin gene region is therefore likely to diminish the association between birth weight and type 1 diabetes.

We can only speculate about biological mechanisms that could explain a hypothetical casual effect of birth weight on risk of type 1 diabetes. Insulin is the most important fetal growth factor late in pregnancy. ${ }^{26}$ In vitro studies have shown that pancreatic $\beta$ cells actively secreting insulin express more antigens associated with diabetes ${ }^{27}$ and are more susceptible to insults by interleukin $1^{28}$ compared with less active $\beta$ cells. Increased growth in utero may therefore lead to an increased risk of later immune mediated destruction of the pancreatic $\beta$ cells. Low birth weight has been associated with impaired cellular immune competence up 
to 5 years of age $\mathrm{e}^{29}$ and with increased mortality from infectious diseases in the age group $1-15$ years. ${ }^{17}{ }^{30}$ Perhaps an impaired cellular immune response makes children less prone to immune mediated destruction of the $\beta$ cells? It has been speculated that the decrease in pancreatic $\beta$ cell mass associated with reduced birth weight is relevant in the association between reduced birth weight and increased risk of type 2 diabetes. ${ }^{31}$ Our findings indicate that a possible reduction in pancreatic $\beta$ cell mass associated with reduced birth weight is not relevant for type 1 diabetes.

\section{Conclusion}

We found a relatively weak but significant association between birth weight and increased risk of childhood onset type 1 diabetes consistent over a wide range of birth weights. It is possible that perinatal factors influence the risk type 1 diabetes, but the mechanisms are unknown.

We thank the staff at the Medical Birth Registry for their assistance.

Contributors: OS and GJ had the original idea for the study, and GJ was the principal investigator. RTL and PM provided advice in presentation and interpretation of the results. LCS was responsible for the data analysis and wrote the paper. All authors commented on the earlier drafts and helped interpret the findings. LCS and GJ are guarantors.

Competing interests: None declared.

Funding: LCS and GJ were supported by a grant from the Norwegian Foundation for Health and Rehabilitation (grant No 1997/156) and a grant from the Norwegian Diabetes Association. Funding was also kindly provided by TINE Norwegian Dairies and Novo Nordisk Pharma A/S.

1 Atkinson MA, Maclaren NK. The pathogenesis of insulin-dependent diabetes mellitus. $N$ Engl J Med 1994;24:1428-36.

2 Leslie DG, Elliott RB. Early environmental events as a cause of IDDM. Diabetes 1994;43:843-50.

3 Dahlquist G, Bennich SS, Källén B. Intrauterine growth pattern and risk of childhood onset insulin dependent (type 1) diabetes: population based case-control study. BMJ 1996;313:1174-7.

4 Podar T, Onkamo P, Forsen T, Karvonen M, Tuomilehto-Wolf E, Tuomilehto J. Neonatal anthropometric measurements and risk of childhoodonset type 1 diabetes. DiMe study group (letter). Diabetes Care 1999;22:2092-4

5 Dahlquist G, Patterson C, Stoltesz G. Perinatal risk factors for childhood type 1 diabetes in Europe: the EURODIAB substudy 2 study group. Diabetes Care 1999;22:1698-702.

6 Blom L, Dahlquist G, Nystrøm L, Sandstrøm A, Wall S. The Swedish childhood diabetes study-social and perinatal determinants for diabetes in childhood. Diabetologia 1989:32:7-13.

7 Kyvik KO, Green A, Svendsen A, Mortensen K. Breast feeding and the development of type 1 diabetes mellitus. Diabetic Med 1991;9:233-5.

8 Lawler-Heavner J, Cruickshanks KJ, Hay WW, Gay EC, Hamman RF. Birth size and risk of insulin-dependent diabetes mellitus (IDDM). Diabetes Res Clin Pract 1994;24:153-9.
9 Johansson C, Samuelsson U, Ludvigsson J. A high weight gain early in life is associated with an increased risk of type 1 (insulin-dependent) diabetes mellitus. Diabetologia 1994;37:91-4.

10 Bock T, Pedersen CR, Volund A, Pallesen CS, Buschard K. Perinatal determinants among children who later develop IDDM. Diabetes Care 1994;17:1154-7.

11 McKinney PA, Parslow R, Gurney KA, Law GR, Bodansky HJ, Williams R. Perinatal and neonatal determinants of childhood type 1 diabetes: a case-control study in Yorkshire, UK. Diabetes Care 1999;22:928-32.

12 Jones ME, Swerdlow AJ, Gill LE, Goldacre MJ. Pre-natal and early life risk factors for childhood onset diabetes mellitus: a record linkage study. Int J Epidemiol 1998;27:444-9.

13 Bache I, Bock T, Vølund A, Buschard K. Previous maternal abortion, longer gestation, and younger maternal age decease the risk of type 1 diabetes among male offspring. Diabetes Care 1999;22:1063-5.

14 Kyvik KO, Bache I, Green A, Beck-Nielsen H, Buschard K. No association between birth weight and type 1 diabetes mellitus-a twin-control study. Diabet Med 2000;17:158-62.

15 EURODIAB ACE Study Group. Variation and trends in incidence of childhood diabetes in Europe. Lancet 2000;355:873-6.

16 Preston DL, Lubin JH, Pierce DA, McConney ME. Epicure user's guide. Seattle: Hirosoft International Corporation, 1993

17 Samuelsen SO, Magnus P, Bakketeig LS. Birth weight and mortality in childhood in Norway. Am J Epidemiol 1998;148:983-91.

18 Joner G, Stene LC, Søvik O, the Norwegian Childhood Diabetes Study Group. No increase in incidence of type 1 diabetes in young children in Norway 1989-1998 (abstract). Diabetologia 2000;43(suppl 1):A27.

19 Stene LC, Ulriksen J, Magnus P, Joner G. Use of cod liver oil during pregnancy associated with lower risk of type I diabetes in the offspring. Diabetologia 2000;43:1083-92.

20 Metcalfe MA, Baum JD. Family characteristics and insulin dependent diabetes. Arch Dis Child 1992;67:731-6.

21 Pedersen CR, Bock T, Hansen SV, Hansen MW, Buschard K. High juvenile body weight and low insulin levels as markers preceding early diabetes in the BB rat. Autoimmunity 1994;17:261-9.

22 Skjærven R, Gjessing HK, Bakketeig LS. Birthweight by gestational age in Norway. Acta Obstet Gynecol Scand 2000;79:440-9.

23 Onkamo P, Väänänen S, Karvonen M, Tuomilehto J. Worldwide increase in incidence of type 1 diabetes-the analysis of the data on published incidence trends. Diabetologia 1999;42:1395-403.

24 Dunger DB, Ong KK, Huxtable SJ, Sherriff A, Woods KA, Ahmed ML, et al. Association of the INS VNTR with size at birth. ALSPAC study team. Avon longitudinal study of pregnancy and childhood. Nature Genet 1998;19:98-100.

25 Bain SC, Prins JB, Hearne CM, Rodrigues NR, Rowe BR, Pritchard LE, et al. Insulin gene region-encoded susceptibility to type 1 diabetes is not restricted to HLA-DR4-positive individuals. Nat Genet 1992;2:212-5.

26 Hill DE. Fetal endocrine pancreas. Clin Obstet Gynecol 1980;23:837-47.

27 Björk E, Kämpe O, Grawe J, Hallberg A, Norheim I, Karlsson FA. Modulation of beta-cell activity and its influence on islet cell antibody (ICA) and islet cell surface antibody (ICSA) reactivity. Autoimmunity 1993;16:181-8.

28 Palmer JP, Helqvist S, Spinas GA, Mølvig J, Mandrup-Poulsen T, Andersen HU, et al. Interaction of $\beta$-cell activity and IL- 1 concentration and exposure time in isolated rat islets of Langerhans. Diabetes 1989;38:1211-6

29 Chandra RK, Ali SK, Kutty KM, Chandra S. Thymus-dependent lymphocytes and delayed hypersensitivity in low birth weight infants. Biol Neonate 1977;31:15-8.

30 Read JS, Clemens JD, Klebanoff MA. Moderate low birth weight and infectious disease mortality during infancy and childhood. Am J Epidemiol 1994;140:721-33.

31 Barker DJP. Mothers, babies and health in later life. 2nd ed. Edinburgh: Churchill Livingstone, 1998.

(Accepted 19 February 2001)

\section{Email submissions from outside the United Kingdom}

We offer an email submission service for authors from outside the UK. The address is papers@bmj.com

Ideally our email server would link seamlessly with our manuscript tracking system, but for now it does not, which is why we are offering the service only to authors outside the UK. Most post in the UK arrives the next day, so UK authors have the least to gain in speed of delivery from email delivery. As soon as our systems improve we will invite email submissions from everyone.

If you choose to send your submission by email please would you send the text and any tables and figures as attached files, together with a covering letter giving all your contact details (postal address, phone, fax, and email address). We can read files created with most word processing, graphics, and spreadsheet programs.

When your submission is received in our email box you will receive an automatic acknowledgment to show that it has arrived. If the submission is incomplete we will contact you and ask you to resend the missing information.

Once the submission is complete we will register it on our manuscript tracking system and you will receive a standard acknowledgment in the post.

Letters to the editor should continue to be sent direct to bmj.com as rapid responses or toletters@bmj.com 